\title{
Deutiches Qejebuch
}

.

$\mathfrak{R a r l} \mathfrak{H e f f e l .}$

Áug̉gabe für $\mathfrak{M a ̈ b d e n j đ u l e n ~}$
mit neunjäbrigem Lebrgang.

\author{
Unter Mitwirfung \\ pon \\ $(\mathfrak{b} \mathfrak{h} \mathfrak{i} \mathfrak{i t} \mathfrak{a} \mathfrak{n} \mathfrak{U} \mathfrak{f} \mathfrak{e r}$. \\ Bierter seil.
}

Für baz fünfte Gđuljabr.

Sm มทุiकlụ

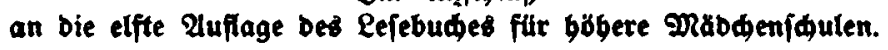

$$
3 \text { onn } 1911 .
$$

2. Marcus uno $\mathfrak{E}$. Webers Berlag. 
